\title{
A study of smart phone addiction and effects on perceived stress in medical students in a tertiary hospital in central India
}

\author{
Abhishek Somani ${ }^{1}$, Amit Nagarkar ${ }^{2}$, Mosam Phirke $^{3}$, Praveer Waradkar ${ }^{4}$ \\ ${ }^{1}$ Associate Professor, Department of Psychiatry, Indira Gandhi Government Medical College and General \\ Hospital, Nagpur \\ ${ }^{2}$ Assistant Professor, Department of Psychiatry, Indira Gandhi Government Medical College and General \\ Hospital, Nagpur \\ ${ }^{3}$ Senior Resident, Department of Psychiatry, Indira Gandhi Government Medical College and General \\ Hospital, Nagpur \\ ${ }^{4}$ Professor and Head, Department of Psychiatry, Indira Gandhi Government Medical College and General \\ Hospital, Nagpur \\ Corresponding author: Amit Nagarkar \\ Email-amitnagarkar2105@gmail.com
}

\begin{abstract}
Background: Usage of smart phones is on the rise not top exclude medical students. Stress among medical students is also known due to various reasons. A study to assess addiction to smart phones in medical students and its relation to the perceived stress in them was planned in a tertiary care hospital in central India. There are 2 aims- 1) To study hours of phone and social media use and smart phone addiction in medical students 2) To study the levels of perceived stress in them and its relation to the levels of smart phone addiction

Methods: Medical students willing to participate in the study and those having android phones were explained the nature of research study and were enrolled after written and informed consent. They were asked to install a free application called app usage tracker from play store so as to track their phone usage. Confidentiality of personal information d data was ensured and informed to participants of the study. Data was collected at end of 7 days. Stress was assessed using perceived stress scale and addiction assessed using smart phone addiction scale. Data was tabulated and analysed using SPSS 17.

Results: 52 males (51.5\%) males and 48 (48.5\%) females participated in the study. Mean age of students 19.4 years (range 17-26)88.1\% were single while others in a relationship. $56.4 \%$ stayed in hostels while others in their family. All of them used android phones. The average use of smart phone was 6.5 hours/ day (range 1-14 hours) as calculated by the phone application. Mean score on students on smart phone addiction scale was 36.16 (range 11-60, mean Cut off being 20, indicating most of the participants were addicted to their smart phones. Mean score on the perceived stress scale was 20.73 indicating that the study participants had moderate levels of stress (14-26). The correlation between smart phone addiction and the perceived stress in students was positive and significant.

Conclusion: The addiction is thus a matter of concern for medical students and their future. It is also pertinent to note that, as the study points out, that medical students are continuously under a moderate level stress. Stressed individuals trying to find solace in their phones are again more vulnerable and at more risk of developing mental illnesses like insomnias, anxiety, depression, substance dependence etc.
\end{abstract}

Keywords: Smartphone addiction, perceived stress, medical students.

(Paper received $-12^{\text {th }}$ September 2018, Peer review completed $-20^{\text {th }}$ October 2018)

(Accepted $-24^{\text {th }}$ October 2018) 


\section{INTRODUCTION}

Smart phones are being increasingly used in India since the last few years. With increase in demand for information and the ease of use and cost effectivity, smart phones are customary with everyone despite differences in the socioeconomic status. According to a study [1] an average person has at least 2 smart phones. The number of internet users in India has increased 8 folds from about 5 million in year 2008 to 42 million in 2008 [2]. Smart phones are making life easier day by day. We can access, get connected, chat or talk in videos with people miles away from us with use of smart phones. Though considered as negative impact of internet use, but smart phones are also used in excessive gaming, gambling and visiting pornography sites. Almost every smart phone has facilities that any highly advanced phone version might have. Nowadays we tend to do all sort of communications like chatting, doing bank transactions, selling, purchasing etc on our smart phones itself. This has on one end made life easier and brought the world at our finger tips but on the other end it has also sort of minimised face to face communications, personal social interactions, physical contacts etc. It has also led to a sedentary life style and emergence of complaints like wrist pain, back pain, joint pain in younger individuals too. Smart phones have started occupying a significant amount of our time that we needed to spend interacting with others personally. Habits like writing, playing outdoor games, reading books, visiting neighbours and friends are on the decrease.

Medical students are usually a younger generation and youth in the making. They comprise usually of individuals in the age group of $18-30$ years and need to spend much of their time in studying medicine and its practical applications. Students are separated from their families and also many feel homesick and stressed. Stress due to studies, newer surroundings, work, patients etc also affect them significantly. People who feel stressed tend to find solace in addictions is and old dictum. Smart phone addiction and internet addictions are one of the emerging and most troublesome forms of addictions which are very difficult to treat amongst all other forms of addictions. There is a high possibility that medical students may have had a tendency to get addicted to their smart phones. Such students are likely to spend lesser time in studies and one to one patient interactions. It is interesting to know the prevalence of smart phone addiction in medical students and its correlation with their stress levels. With this in mind a study was planned to investigate the same in a government medical college with an attached tertiary care hospital.

\section{METHODOLOGY}

\section{Aims and Objectives:}

1) To calculate the average time of smart phone use and use of social media among medical students

2) To assess smart phone addiction in medical students

3) To assess levels of perceived stress in medical students

4) To find correlation between smart phone addiction and perceived stress in medical students

All the participants in the study were duly informed in detail about nature and scope of the study. Students were assured of the confidentiality of their information and phone data. The purpose and research objectives of the study were also explained in details to them. A written informed consent was taken from them before starting the study allowing them to withdraw from the study in between if they feel like. A semi structured proforma was prepared to collect demographic details about the participant and his/ her phone details (whether uses phone or not, type of phone, operating software). An android application called the App usage tracker was selected to study the hours of usage of smart phone and social media on phones. The application is available on android play store free of cost. Participants in the study were asked to download the same application on their respective smart phones. They were instructed not to delete or reset the application during the course of their study unless they wish to stop being a part of the study. Students were explained that the application won't be gathering any personal/ private information from their smart phones apart from what the study intends to do. Students were instructed to continue using their phones in the same usual way as they did and report back at the end of exact 7 days. Reporting times were specified to every individual personally. At the end of 7 days the data from the android application was imported via emails from every participant. At the same time students were also assessed for addiction to their phones and levels of perceived stress in them. This was done using 2 different self assessment scales, the Smart phone addiction scale and 
Perceived stress scale. Data thus collected from the participants was pooled and tabulated and subjected to statistical analysis using the SPSS 17.

\section{RESULTS}

The study sample consisted of 101 medical students who enrolled themselves into the study after consenting and completed the study with no drop outs. The sample had $51.5 \%$ male $(n=52)$ and $48.5 \%$ female $(n=49)$ medical students. All of them were using smart phones, all being android phones. More than half of them i.e. $56.4 \%(n=57)$ stayed in the hostel away from their families while $43.65 \%(n=44)$ stayed back home with their family. The mean age of the patients was around 19.4 years. The youngest student was 17 years while the eldest was 26 years old. The mean time for which students had been using their mobile phones was reportedly around 2 years ( 24.25 months, ranging from 7 months to 6.5 years). When asked only 12 students out of $100(11.9 \%)$ reported to be in a relationship with someone while 89 students $(88.1 \%)$ maintained that they were still single.

Table 1: Demographic data and general information of the participants

\begin{tabular}{|lll|}
\hline & Mean & Range \\
\hline Age of students & 19.4 years & $17-26$ years \\
\hline Time since mobile use & 24.25 months & $7-78$ months \\
\hline
\end{tabular}

Addiction to smart phones was assessed according to the time spent by each student using the phone. An application available free of cost on the android play store and that could be easily downloaded on the participants phone, was selected. Once set the application called the App usage tracker could calculate the hours spent per day by the participant on his/ her phone. The participants were instructed in detail that once downloaded and set, they should not reset, stop, alter or delete the application from their respective smart phones (unless they have decided to quit from the study). The participants were ensured that their personal details and internet browsing data was private and won't be tracked by the application. At the end of 7 days the hours spent by the participants every day on the smart phone was available through the application. The data was imported through emails from participants.

The average number of hours spent on the smart phone by medical students was found to be 6.5 hours per day, the range being 1-14 hours/ day.

Similarly, addiction to smart phones was assessed using the smart phone addiction scale (SAS, short version). The mean score of the participants in our study was 36.16 , range being $11-60$, which was fairly high. The cut off for addiction was 20 in the scale. Thus, most of the medical students were found to be addicted to their smart phones.

\section{Stress among medical students}

Stress in the participants was assessed using the perceived stress scale (PSS) which is a self-assessment scale. Students reported a mean score of 20.73 which falls in the moderate category of stress (14-26, according to the scale). Medical students were thus found to be under moderate levels of stress according to the study.

\section{DISCUSSION}

The study revealed that majority of medical students were addicted to their smartphone and social media use. $95.5 \%$ students used phones for at least 6.5 hours a day which made them addicted to their phones. Since one third of their day is spent using their phone a lot of productive time is thus lost. Medical" students in the age group of 18-27 years are expected to spend a major part of their day that is around 6-7 hours in lectures, demonstrations, tutorials, reading books and learning and practicing medical skills. Time spent on phone thus kills their rest of the time too which they should have spent on relaxation, having a sound sleep, talking to friends or doing something productive etc. Excessive phone use may cause eye strain, increased irritability, compulsive behaviours, insomnias, depression, anxiety, disturbed social relations etc. The addiction is thus a matter of concern for medical students and their future. It is also pertinent to note that, as the study points out, that medical students are continuously under a moderate level stress. Stressed 
individuals trying to find solace in their phones are again more vulnerable and at more risk of developing mental illnesses like insomnias, anxiety, depression, substance dependence etc. Thus, it is a suggestion worthwhile to ponder that medical students should undergo regular psychiatric check-ups especially the ones who are used to excess phone use.

Table 2: Correlations of SAS and PSS with demographic variables

\begin{tabular}{|lcccc|} 
& Male (n=52) & $\begin{array}{l}\text { Female } \\
(\mathbf{n}=49)\end{array}$ & $\mathbf{t}$ value & \\
\hline Age (in years) & $19.63 \pm 1.25$ & $19.14 \pm 0.61$ & 1.99 & $0.012^{*}$ \\
\hline Smart Phone Use (hour per day) & $6.84 \pm 2.93$ & $6.12 \pm 2.06$ & 1.40 & $0.019^{*}$ \\
\hline $\begin{array}{l}\text { Total duration of phone use } \\
\text { (in months) }\end{array}$ & $27.27 \pm 17.56$ & $21.04 \pm 13.40$ & 2.48 & 0.083 \\
\hline $\begin{array}{l}\text { Watching pornographic content (in } \\
\text { hours) }\end{array}$ & $0.28 \pm 0.71$ & $0.04 \pm 0.28$ & 2.14 & $<0.01^{* *}$ \\
\hline Total Score (SAS) (cut off = 20) & $37.25 \pm 9.77$ & $35.00 \pm 7.96$ & 1.26 & 0.287 \\
\hline Total Score (PSS) & $20.07 \pm 5.92$ & $21.42 \pm 5.07$ & -1.22 & 0.273 \\
\hline $\begin{array}{l}\text { Age (In Years) } \\
\text { (In) }\end{array}$ & $19.42 \pm 1.01$ & $19.16 \pm 1.11$ & 0.82 & 0.78 \\
\hline $\begin{array}{l}\text { Smart Phone Use } \\
\text { (Per hour per day) }\end{array}$ & $6.28 \pm 2.47$ & $8.00 \pm 2.79$ & -2.22 & 0.63 \\
\hline $\begin{array}{l}\text { Total duration of phone use } \\
\text { (in months) }\end{array}$ & $24.53 \pm 16.15$ & $22.08 \pm 14.50$ & 0.50 & 0.79 \\
\hline $\begin{array}{l}\text { Watching pornographic } \\
\text { content (in hours) }\end{array}$ & & & & \\
\hline $\begin{array}{l}\text { Total Score (SAS) } \\
\text { (cut off = 20) }\end{array}$ & $0.14 \pm 0.56$ & $0.25 \pm 0.45$ & -0.60 & 0.46 \\
\hline Total Score (PSS) & $35.82 \pm 8.64$ & $38.66 \pm 11.19$ & -1.03 & 0.20 \\
\hline & $20.68 \pm 5.72$ & $21.08 \pm 4.12$ & -0.23 & 0.22 \\
\hline
\end{tabular}

Table 3: Usage of Smartphone

\begin{tabular}{|lllll|}
\hline & Hostel & With Family & t value & $\mathbf{p}$ \\
\hline Age (In Years) & $19.45 \pm 0.68$ & $19.31 \pm 1.34$ & 0.67 & 0.94 \\
\hline $\begin{array}{l}\text { Smart Phone Use } \\
\text { (Per hour per day) }\end{array}$ & $6.41 \pm 2.41$ & $6.60 \pm 2.77$ & 0.35 & 0.72 \\
\hline $\begin{array}{l}\text { Total duration of phone use } \\
\text { (in months) }\end{array}$ & $22.98 \pm 15.99$ & $25.88 \pm 15.85$ & -0.07 & 0.50 \\
\hline $\begin{array}{l}\text { Watching pornographic } \\
\text { content (in hours) }\end{array}$ & $0.18 \pm 0.61$ & $0.12 \pm 0.46$ & 1.06 & 0.28 \\
\hline $\begin{array}{l}\text { Total Score (SAS) } \\
\text { (cut off = 20) }\end{array}$ & $37.47 \pm 9.66$ & $34.45 \pm 7.76$ & 0.92 & 0.35 \\
\hline Total Score (PSS) & $19.64 \pm 6.31$ & $12.13 \pm 3.99$ & -0.45 & 0.65 \\
\hline
\end{tabular}


Table 4: Statistical inference of usage of smartphones

\begin{tabular}{|lllll|} 
& $\begin{array}{l}\text { Addicted } \\
(\mathbf{n = 9 6 )}\end{array}$ & Non (n=5) & $\begin{array}{l}\mathbf{t} \\
\text { value }\end{array}$ & $\mathbf{p}$ \\
\hline Age (In Years) & $19.40 \pm 1.03$ & $19.20 \pm 0.83$ & 0.43 & 0.20 \\
\hline Smart Phone Use (hour per day) & $6.63 \pm 2.50$ & $3.80 \pm 2.38$ & 1.27 & $0.01^{* *}$ \\
\hline $\begin{array}{l}\text { Total duration of phone use } \\
\text { (in months) }\end{array}$ & $24.70 \pm 16.14$ & $15.40 \pm 6.76$ & 2.47 & 0.66 \\
\hline $\begin{array}{l}\text { Watching pornographic content } \\
\text { (in hours) }\end{array}$ & $0.15 \pm 0.56$ & $0.20 \pm 0.44$ & -0.16 & 0.86 \\
\hline Total Score (PSS) & $21.04 \pm 5.23$ & $14.80 \pm 8.40$ & 2.51 & $0.01^{* *}$ \\
\hline
\end{tabular}

\section{LIMITATIONS}

- The application monitored phone use only during 7 days

- The app usage tracker does not operate in IOS phones.

- The smart phone addiction scale and perceived stress scale both were self assessment scales

- Possibility of participants resetting the application during the observation period cannot be ruled out.

\section{REFERENCES}

1. Kwon M, Kim DJ, Cho H, Yang S. The smartphone addiction scale: development and validation of a short version for adolescents. PloS One 2013;8(12):e83558.

2. Andreou E, Alexopoulos EC, Lionis C, Varvogli L, Gnardellis C, Chrousos GP, Darviri C. Perceived stress scale: reliability and validity study in Greece. Int J Environ Res Pub Health 2011;8(8):3287-98.

3. Kim BN, Ko EJ, Choi HI. A study on factors affecting smart-phone addiction in university students: A focus on differences in classifying risk groups. Studies on Korean Youth 2013;24(3):67-98.

4. Kim BN. Effect of Smart-phone Addiction on Youths Sociality Development. J Korea Contents Assoc 2013;13(4):208-17.

5. Harshe D, Karia S, Rajani S, Bharati A, De Sousa A, Shah N, Mishra P. Smartphone usage practices, preferences and its perceived effects in medical students at a tertiary care medical college. Int J Med Pub Health 2017;7(1):20-4.

6. Davey S, Davey A. Assessment of smartphone addiction in Indian adolescents: a mixed method study by systematic-review and meta-analysis approach. Int J Prev Med 2014;5(12):1500-6.

7. Al-Barashdi HS, Bouazza A, Jabur, NH. Smartphone addiction among university undergraduates: a literature review. J Scientific Res Reports 2015;4(3):210-25.

8. Samaha M, Hawi NS. Relationships among smartphone addiction, stress, academic performance, and satisfaction with life. Comp Hum Behav 2016;57:321-5.

9. Bogomolov A, Lepri B, Ferron M, Pianesi F, Pentland AS. Daily stress recognition from mobile phone data, weather conditions and individual traits. InProceedings of the 22nd ACM international conference on Multimedia 2014 Nov 3 (pp. 477-486). ACM.

10. Singh JD, Yadav RA. Health complications caused by excessive use of smartphones. Glob J Multidiscpl Stud 2015;4(2).

$* * * * * * * * * * * * * * * * * * * * * * * * * * * * * * * * * * * *$

Acknowledgements - Nil

Conflict of Interest - Nil

Funding - Nil 